\title{
TAXA DE CÂMBIO SOCIAL E ABERTURA COMERCIAL ${ }^{*}$
}

Léo da Rocha Ferreira ${ }^{\S}$

\begin{abstract}
RESUMO
O objetivo geral deste artigo é avaliar o impacto da abertura comercial brasileira na taxa de câmbio social. O seu objetivo específico é desenvolver e calcular uma medida apropriada para a taxa de câmbio social a ser utilizada na análise de projetos de investimentos no Brasil. Utilizando um modelo de custo de oportunidade da divisa para estimar taxa de câmbio social, o estudo conclui que não houve alteração importante no ordenamento das atividades econômicas segundo o grau de proteção efetiva. A tendência declinante da taxa de câmbio social é resultado da abertura comercial iniciada no final dos anos oitenta e da mudança da política cambial brasileira de janeiro de 1999.
\end{abstract}

Palavras-chave: abertura comercial, avaliação de projetos, taxa de câmbio social e política cambial.

\begin{abstract}
The purpose of this paper is to analyze the impact of the trade liberalization process on social exchange rates in Brazil. The main objective is to develop and estimate an appropriate measure for the social exchange rates to be used in the evaluation of investment projects in Brazil. Using an opportunity cost for foreign exchange model to estimate the social exchange rates, the study concludes that there were no important modifications in the ranking of economic activities according to the rates of effective protection. The impact of the trade liberalization process and the change in exchange rate policy regime will only be fully measured in the medium and long run. However, an indication of its effects on the social exchange rates can clearly be observed by the declining tendency of the social exchange rates.
\end{abstract}

Key words: trade liberalization, project appraisal, social exchange rates and exchange rate policy.

JEL classification: H43, F31.

\footnotetext{
O autor agradece as sugestões e os valiosos comentários de Paulo Fernando Cidade de Araújo e William G. Tyler a versões anteriores deste artigo. Também agradece a um parecerista anônimo cujas sugestões melhoraram substancialmente o artigo. Cabe registrar o competente trabalho de revisão bibliográfica, coleta de dados e computacional do estagiário Leandro Fernandes Caruso e sua atualização pelos estagiários Pedro Henrique Costa Motta e Sylvio Saraiva.

$\S$ Professor Titular da Faculdade de Ciências Econômicas e Coordenador do Programa de Pós-Graduação em Ciências Econômicas da UERJ.

Recebido em outubro de 2004. Aceito em agosto de 2005.
} 


\section{INTRODUÇÃO}

As taxas de câmbio desempenham um papel essencial no comércio internacional, dado que suas variações modificam a escala de preços entre os países.

Nos países desenvolvidos e industrializados, a flexibilização do câmbio só ganhou maior impulso no início dos anos setenta com a abertura e a integração financeira dos mercados. Já nos anos noventa, esse processo se acelerou mais ainda, alcançando os países emergentes. Muitos consideravam essa integração inevitável, tendo em vista a ampliação do comércio mundial, o papel das multinacionais e os avanços tecnológicos da informática e das comunicações. A liberação cambial faz parte da ampliação do movimento internacional de capitais. Neste contexto, a política de câmbio flexível passou a ser um instrumento adicional importante na ampliação do movimento de capitais entre países e regiões. ${ }^{1}$

No Brasil, o processo de liberação cambial ganhou velocidade no início de 1999, quando o País foi obrigado a abandonar o regime de banda cambial. Durante muito tempo, era uma verdadeira heresia falar em preços livres. Do mesmo modo, a defesa do comércio internacional livre era também considerada um contra-senso. Contudo, os acontecimentos ocorridos durante os anos noventa derrubaram esses dois tabus. O que se observa hoje é que os preços praticados no País são livres e a economia brasileira já é, consideravelmente, aberta. Um terceiro tabu vai aos poucos sendo quebrado. ${ }^{2}$ Trata-se do controle cambial. O câmbio flutuante pode ser visto, por muitos, como uma conquista histórica da política econômica.

O objetivo geral deste artigo é avaliar o impacto do processo de abertura comercial na taxa de câmbio social no Brasil. O seu objetivo específico é desenvolver e calcular uma medida apropriada para a taxa de câmbio social a ser utilizada na análise de projetos de investimentos no Brasil.

A divergência entre taxa de câmbio de mercado e taxa de câmbio social é algo que não pode ser ignorado na avaliação de projetos. Caso não sejam feitos os ajustes necessários, poderá haver uma sub ou superestimativa dos benefícios e custos do projeto. Antes da mudança do regime cambial de janeiro de 1999 havia um consenso, entre os especialistas da área, que em um regime de câmbio fixo a taxa de câmbio social supera a taxa oficial e/ou a taxa de mercado. Se isto for correto, a adoção de um regime cambial com taxas de câmbio flexíveis deverá contribuir para uma redução significativa da diferença entre taxa de câmbio social e taxa oficial e/ou taxa de mercado. Neste sentido, a estimativa da taxa de câmbio social permitirá a verificação empírica desta hipótese. A literatura econômica é abundante em relação às alternativas metodológicas para o cálculo da taxa de câmbio social. ${ }^{3}$

A grande maioria dos países emergentes, com o intuito de melhorar o nível de vida das suas populações e evitar desperdícios, costuma utilizar um sistema de planejamento econômico para ordenar as prioridades e a distribuição dos recursos escassos. Os projetos constituem a última etapa de um progra-

1 Isto não quer dizer, necessariamente, que se o câmbio fosse fixo, não teríamos tido um aumento significativo nos movimentos de capitais.

2 Veja por exemplo, o trabalho de Gonçalves (1996) que, ao examinar o processo de liberalização cambial em andamento no Brasil, no contexto da globalização financeira, em suas conclusões, na página 163 afirmava: “... dificilmente pode-se escapar à recomendação de se dar um retrocesso no processo de liberação cambial, com limitações a despesas na conta de serviços e maior controle sobre entradas e saídas na conta de capital." Licha (2001) advoga a intervenção do Banco Central no mercado futuro do dólar norteamericano, de forma a afetar as expectativas de desvalorização. Em entrevista publicada no Jornal dos Economistas ( $\mathrm{n}^{\circ}$ 145, Julho de 2001, p. 10), o economista Ricardo Carneiro, da Universidade Estadual de Campinas, respondendo a uma pergunta sobre se o câmbio no Brasil deve permanecer flutuante, afirmou: “... o Brasil será vítima, nos próximos meses, de um ataque especulativo em razão do default argentino e da fragilidade de nossas contas externas. Passado esse momento será possível avaliar quais as políticas e os instrumentos que devem ser mantidos ou reformulados."

3 Para uma discussão a respeito das alternativas metodológicas de cálculo da taxa de câmbio social, e estudos empíricos no Brasil, consultar o Capítulo 6 de Contador (2000). 
ma coordenado de investimentos deste sistema de planejamento. ${ }^{4}$ Do ponto de vista econômico, um projeto nada mais é do que um plano de investimento, ou seja, é a avaliação das vantagens e desvantagens da utilização de recursos escassos da sociedade para a criação de novos meios de produção ou para o aumento da capacidade de produção existente.

Com a globalização e a ampliação das relações comerciais internacionais, a divergência entre a taxa de câmbio oficial ou de mercado e a taxa social é algo que não pode ser ignorado na avaliação de projetos. Como antes afirmado, caso não sejam feitos os ajustes necessários, haverá uma sub ou superestimativa dos custos e dos benefícios do projeto. Em conseqüência, os preços de mercado não refletirão, necessariamente, os preços sociais. Deste modo, há necessidade de se proceder aos ajustes necessários na taxa de câmbio. Com este objetivo mais amplo, e à luz da literatura existente, um modelo específico foi adaptado às condições brasileiras para o cálculo da taxa social de câmbio. Sempre que um projeto possa afetar o balanço de pagamentos de um país, os seus itens calculados em moeda estrangeira deverão sofrer os reajustes necessários com a utilização da taxa social de câmbio.

\section{Metodologia}

\subsection{Preliminares}

A literatura pertinente apresenta inúmeras alternativas metodológicas para o cálculo da taxa de câmbio social. ${ }^{5}$ A partir dos objetivos do artigo, foi avaliada a possibilidade da utilização de enfoques metodológicos alternativos mais indicados, como: a taxa de câmbio de equilíbrio e o custo social da geração de divisas.

O argumento da taxa de câmbio de equilíbrio compreende diversas versões. A versão mais simples adota como taxa de câmbio social aquela relação de troca ou câmbio de paridade entre duas moedas que fornece idêntico valor de mercado numa cesta típica de bens e serviços. A metodologia do cálculo do custo social da divisa consiste em decompor a função de oferta de divisas com o objetivo de comparar o custo de oportunidade das várias formas de ampliar a oferta de divisas. Esta abordagem está relacionada com o princípio ricardiano da vantagem comparativa no comércio mundial. Para a análise empírica foram utilizados dados secundários apresentados na Tabela 1 e no Apêndice. Os dados da balança de pagamentos são apresentados na Tabela A.1; a taxa de câmbio nominal e a taxa de câmbio efetiva real no Brasil, para o período 1980/2003, são mostradas na Tabela A.2; as tarifas nominal e efetiva no Brasil, para o período 1987/2003, são apresentadas na Tabela A.3; e as estimativas de elasticidade-preço de exportação e importação são mostradas na Tabela 2.

\subsection{Taxa de câmbio e tarifa aduaneira}

A evolução do índice da taxa de câmbio nominal e taxa de câmbio efetiva real no Brasil, para o período 1980/2003, é mostrada na Figura 1. Nos anos 80, a crise da dívida externa brasileira determinou uma política de estímulo às exportações, enquanto as importações foram mantidas em baixos patamares.

\footnotetext{
4 Na prática, é comum a elaboração de um projeto sem qualquer integração a um plano global ou setorial.

5 As principais alternativas metodológicas utilizadas para o cálculo da taxa social de câmbio são: programação linear e não linear; custo de oportunidade da divisa; taxa de câmbio de equilíbrio; e custo social da geração de divisa. Suas limitações são discutidas em Contador (2000, op. cit).
} 
Taxas de câmbio reais e o revigoramento da estrutura de proteção comercial constituíram instrumentos essenciais para tanto. Isto pode ser observado pela oscilação da taxa de câmbio efetiva real na Figura 1. Inicialmente, oscila em um mesmo patamar até alcançar o seu valor máximo em 1987.

\section{Figura 1 - Evolução do índice da taxa de câmbio nominal e efetiva real}

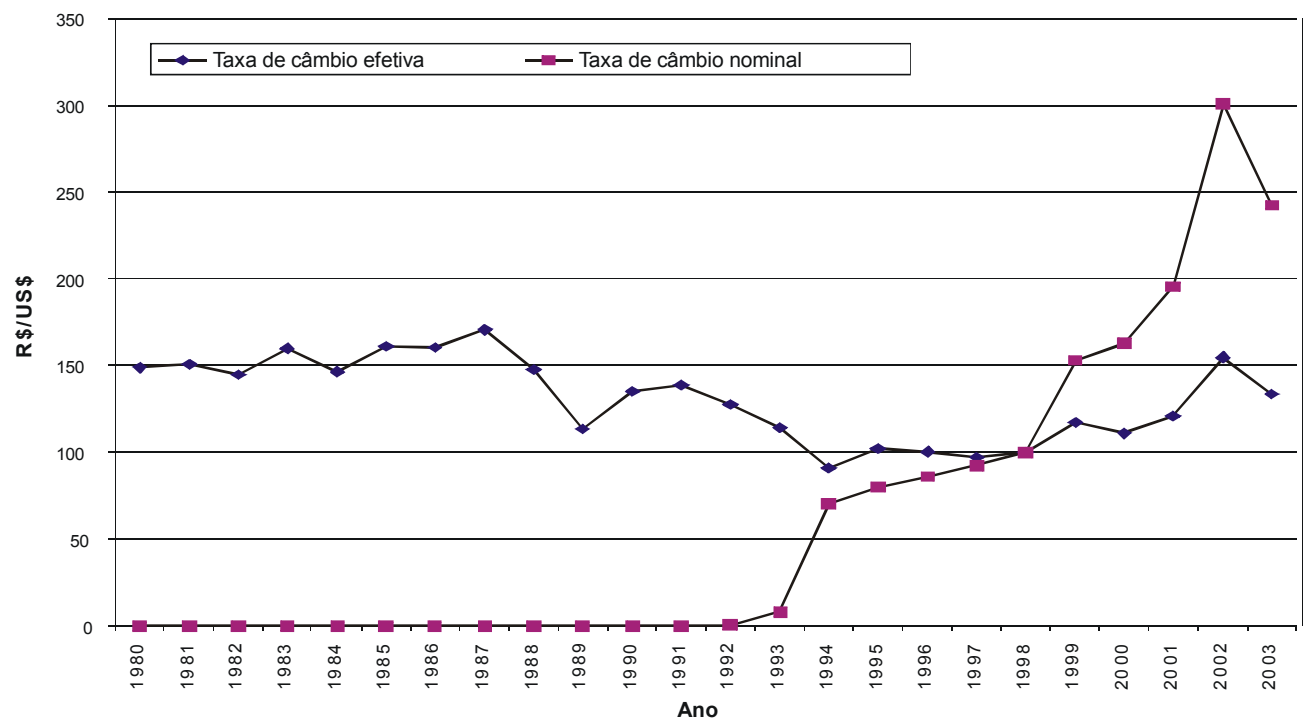

A partir de 1987 há uma queda acentuada da taxa de câmbio efetiva real, fazendo a sua oscilação alcançar um patamar mais abaixo. O seu valor mínimo é atingido em 1994, quando então volta a subir para depois cair no final de 1994, quando então se estabiliza até 1998.

Já na primeira metade dos anos 1990 ocorreu uma forte ascensão das importações, a partir da liberalização comercial e financeira. Neste segundo caso, para permitir a entrada dos capitais que se dirigiam à América Latina. Mesmo com um crescimento médio anual de 8,2\% nas exportações, durante o período 1990/1995, os significativos saldos comerciais positivos reduziram-se a partir do ano de 1992, até mudarem de sinal a partir do último trimestre de 1994.

A introdução do câmbio flutuante em 1999 acarretou novo incremento na taxa de câmbio efetiva real, passando a flutuar abaixo da taxa de câmbio nominal (Figura 1).

A evolução da tarifa nominal e efetiva no Brasil, para o período 1987/2003, é apresentada na Tabela A.3 do Apêndice. Como pode ser observado, no Brasil o processo de abertura comercial acarretou uma redução da tarifa nominal de $49 \%$ a $14,4 \%$ para os bens de capital e de 57,5\% a 9,2\% para os demais bens importados e uma redução da tarifa efetiva de $47,5 \%$ para aproximadamente $18 \%$ para os bens de capital e de $77,1 \%$ a $18,4 \%$ para os demais bens importados no período considerado.

As principais estimativas do coeficiente de elasticidade-preço de exportação e importação feitas para o Brasil são mostradas na Tabela 1 do Apêndice.

\subsection{Taxa de câmbio social}

O conceito de taxa de câmbio social no Brasil, amplamente utilizado na avaliação econômica ou social de projetos, é formalizado nos trabalhos pioneiros desenvolvidos por Bacha e Taylor (1971). ${ }^{6}$

6 Veja os trabalhos de Bacha (1970) e Bacha e Taylor (1971). 
Há uma ampla aceitação entre os economistas de que a taxa de câmbio social seja, normalmente, superior à taxa oficial ou taxa de mercado. Em decorrência, vale dizer que os benefícios sociais (diretos) com uma exportação ou com uma redução nas importações são superiores aos respectivos valores em unidades da moeda, do mesmo modo que os custos sociais (diretos) com uma importação ou com uma redução nas exportações superam a conversão em unidades da moeda à taxa cambial vigente.

Os efeitos de um projeto sobre a balança de pagamentos de um país podem ser de três tipos: (a) aumento nas exportações, em decorrência do bem ou serviço produzido; (b) incremento nas importações dos equipamentos e insumos necessários; e (c) redução na importação de um bem similar ou substituto.

O conceito e uma metodologia própria para estimar a taxa de câmbio virtual são desenvolvidos em trabalho publicado por Pinto (1989). Este conceito pode ser útil na presença de objetivos não-econômicos a serem alcançados por uma sociedade, como, por exemplo, a redução da sua dependência com relação ao setor externo. Qualquer objetivo diferente da maximização da renda real pode ser definido como não-econômico. ${ }^{7}$ No caso da decisão de diminuir a dívida externa líquida, cabe procurar fazê-lo com o menor sacrifício possível da renda real. A principal diferença entre os dois conceitos é que a taxa de equilíbrio social não considera a possibilidade de se usar a política fiscal como instrumento para afetar a balança de pagamentos. Adicionalmente, a teoria do bem-estar mostra que a escolha de uma política adequada depende, basicamente, da razão pela qual se escolhe permitir que o desequilíbrio da balança comercial persista. Visto a sua incapacidade em explicitar a razão deste desequilíbrio, torna-se difícil interpretar a taxa de câmbio social à luz da teoria do bem-estar.

\subsection{Modelo do custo de oportunidade da divisa}

Para avaliar o impacto de mudanças na política comercial e cambial de um país é preciso analisar o seu resultado em relação aos benefícios e aos custos sociais gerados pela implantação de projetos.

Um enfoque metodológico bastante utilizado é o custo de oportunidade da divisa. Os modelos de custo de oportunidade da divisa são geralmente os mais simples e baseados na teoria estática do comércio internacional. Neste raciocínio, a existência ou não de distorções no funcionamento dos mercados domésticos de fatores; a política tarifária; a existência de quotas, proibições, acordos preferenciais entre nações, dumping, e outras barreiras ao comércio internacional são considerados dados. Deste modo, os benefícios e os custos sociais gerados por um determinado projeto são calculados a partir de uma situação real e, evidentemente, não a partir de uma situação ideal. Conseqüentemente, o cálculo da taxa de câmbio social, com este enfoque metodológico, exige um modelo mais genérico. ${ }^{8}$

A participação do Brasil no total do comércio mundial, no ano 2003, correspondeu a menos de $1 \% .{ }^{9}$ Conseqüentemente, a hipótese de país pequeno, usual em economia internacional, pode ser aplicada ao caso brasileiro, dado que a sua economia tem uma participação marginal no total

7 Os objetivos não-econômicos surgiram a partir de uma discussão entre Malthus e Ricardo a respeito dos ganhos do comércio. O conceito foi reintroduzido na literatura econômica por Corden (1984).

8 O desenvolvimento teórico e a popularização deste enfoque são devidos a Arnold C. Harberger da Universidade de Chicago. O tratamento é, em linha geral, semelhante ao adotado para o custo social de outros insumos discutido por Contador (2000). Embora Harberger (1972) adote as tarifas e os subsídios sobre a importação e a exportação como as únicas distorções, não há maiores dificuldades em expandir o raciocínio para considerar também as distorções nos mercados de fatores.

9 De acordo com dados da Secretaria de Comércio Exterior (SECEX), do Ministério do Desenvolvimento, Indústria e Comércio Exterior, a participação das exportações e das importações brasileiras em 2003, em relação ao total mundial, foi de 0,88\% e $0,89 \%$, respectivamente. 
das importações e exportações mundiais. Em decorrência, os preços internacionais não são afetados pela maior importação ou exportação realizada pelo país. ${ }^{10}$

A exportação e a importação de um bem ou serviço qualquer são obtidas a partir do excesso de oferta e demanda doméstica, respectivamente. Na argumentação que se segue, será imposta a hipótese de os preços internacionais serem dados ao país.

Para simplificar a exposição do modelo, admite-se uma economia hipotética com apenas dois produtos: um produto tipicamente de exportação e outro tipicamente de importação. Inicialmente, a taxa de câmbio está fixa em $\mathrm{E}_{0}$, situação em que o país tem um déficit na balança comercial no valor de $\mathrm{M}_{0}-\mathrm{X}_{0}$. A Figura 2 reproduz as condições do modelo, onde o valor em dólares do produto de exportação está indicado por X e o do produto de importação por M. ${ }^{11}$

Para reduzir o déficit da balança comercial, o governo pretende adotar uma política de substituição de importações, incentivando, assim, a produção local do produto tipicamente de importação, a fim de reduzir as suas importações de $\mathrm{M}_{0}$ para $\mathrm{M}_{0}{ }_{0}$. Com isto, a demanda por dólares retraise de DD para D'D', tal que o déficit $\mathrm{M}_{0}-\mathrm{X}_{0}$ é agora compatível com a taxa de câmbio mais baixa $\mathrm{E}_{1}$. Observa-se que, por construção gráfica, a distância $\mathrm{M}_{0}-\mathrm{X}_{0}$ é igual a $\mathrm{M}_{1}-\mathrm{X}_{1}$.

Figura 2 - Efeitos de um projeto na balança comercial: a substituição de importações

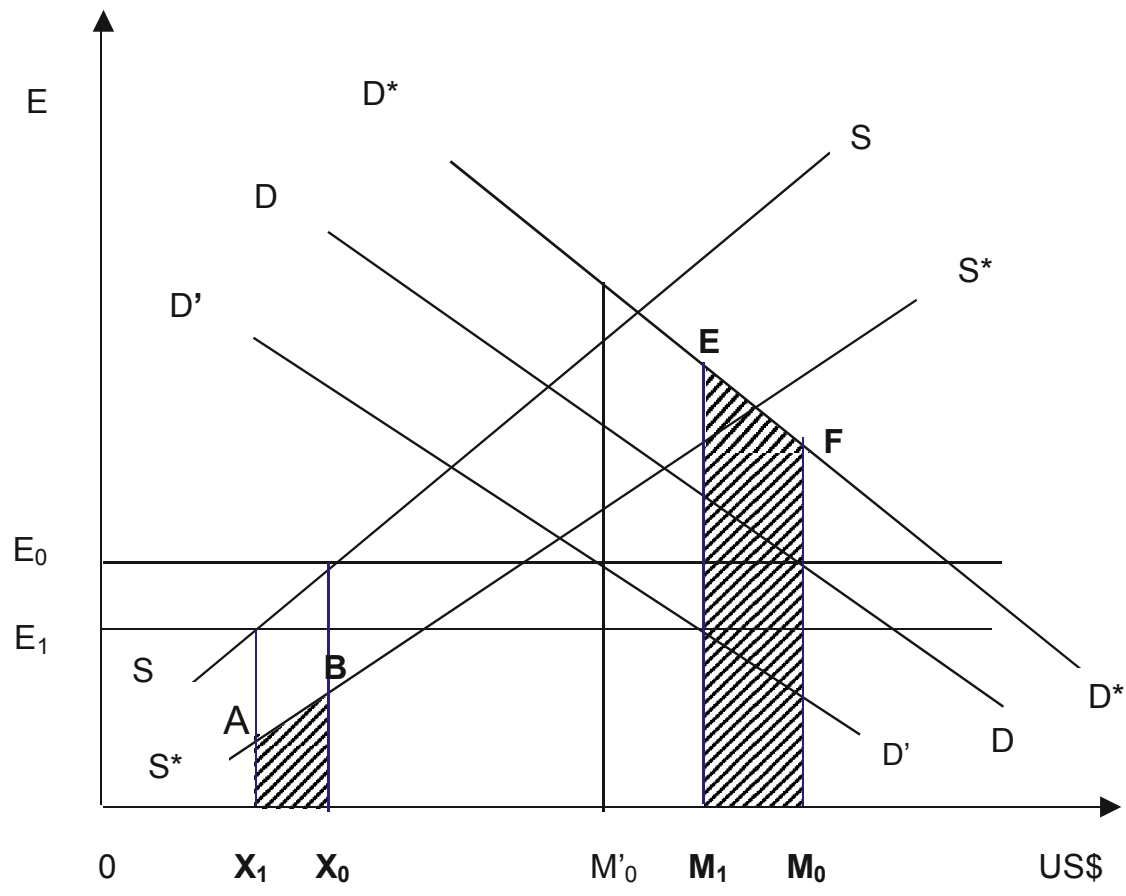

A taxa de câmbio mais baixa, ou seja, uma redução de $\mathrm{E}_{0}$ para $\mathrm{E}_{1}$ tem o efeito de reduzir as exportações de $\mathrm{X}_{0}$ para $\mathrm{X}_{1}$. Em conseqüência, há um benefício para a economia como um todo

10 Esta hipótese pode ser inexata para alguns produtos, como, por exemplo, a de que as exportações de soja pelo Brasil afetam o preço internacional. O minério de ferro é outro produto básico que o Brasil começa a influir na formação do preço mundial, e seria possível encontrar outros exemplos.

11 A notação e a exposição gráfica aqui empregadas, no desenvolvimento do modelo de custo de oportunidade de Harberger, seguem de perto a utilizada por Contador (2000, op. cit). 
com a poupança de fatores domésticos e um menor sacrifício dos consumidores domésticos. ${ }^{12} \mathrm{O}$ benefício social líquido com a queda nas exportações corresponde à área hachurada abaixo da curva $\mathrm{S}^{*} \mathrm{~S}^{*}$, ou seja, o trapézio $\mathrm{X}_{1} \mathrm{ABX}_{0}$. Por outro lado, à taxa de câmbio $\mathrm{E}_{1}$, o produto importado torna-se mais barato, o que induz uma queda no preço do correspondente produto nacional. No final, há um benefício para os consumidores domésticos e uma poupança de fatores com menor produção nas plantas já existentes. Para facilitar o entendimento da exposição, imagina-se que a substituição das importações está sendo feita à custa da implantação de novas fábricas. O benefício com o aumento das importações corresponde à área hachurada $\mathrm{M}_{1} \mathrm{EFM}_{0}$. Portanto, o projeto, ao afetar potencialmente a balança comercial em $\mathrm{M}_{0}-\mathrm{M}_{0}^{\prime}$, corresponde a um benefício total de $\mathrm{X}_{1} \mathrm{ABX}_{0}$ mais $\mathrm{M}_{1} \mathrm{EFM}_{0}$. Daí o custo de oportunidade por unidade de divisa corresponder, em termos figurados, a

$$
E^{*}=\frac{X_{1} A B X_{0}+M_{1} E F M_{0}}{M_{0}-M_{0}^{\prime}}
$$

ou seja, aproximadamente

$$
E^{*}=\frac{\Delta X \cdot E_{s}^{*}+|\Delta M| E_{d}^{*}}{\Delta X+|\Delta M|}
$$

ou ainda,

$$
E^{*}=E\left[\frac{\Delta X\left(1+t_{x}^{*}\right)^{-1}+|\Delta M|\left(1+t_{m}^{*}\right)}{\Delta X+|\Delta M|}\right]
$$

Operando-se algebricamente, tem-se que:

$$
E^{*}=E\left[\frac{\varepsilon^{\prime} X\left(1+t_{x}^{*}\right)^{-1}+\left|\eta^{\prime}\right| M\left(1+t_{m}^{*}\right)}{\varepsilon^{\prime} X+\left|\eta^{\prime}\right| M}\right]
$$

Onde:

$\mathrm{E}^{*}=$ custo de oportunidade da divisa;

$\mathrm{E}=$ taxa de câmbio vigente;

$\varepsilon^{\prime}=$ elasticidade-preço da oferta de exportação;

$\eta^{\prime}=$ elasticidade-preço da demanda de importação;

$\mathrm{X}=$ valor da exportação em dólares;

$\mathrm{M}=$ valor da importação em dólares;

$\mathrm{t}_{\mathrm{x}}{ }_{\mathrm{x}}=$ distorções no mercado de fatores e tarifas sobre as exportações; e

$\mathrm{t}_{\mathrm{m}}=$ distorções no mercado de fatores e tarifas sobre as importações.

12 Para um maior detalhamento, o leitor em dúvida sobre este ponto poderá consultar o Capítulo 6 de Contador (2000, op. cit., especialmente as Figuras 6.7 e 6.10 ). 
Outro exemplo seria o caso de um projeto que ampliasse as exportações do produto tipicamente de exportação, e a dúvida seria a que taxa de câmbio as exportações adicionais deveriam ser valorizadas. A Figura 3 mostra este caso. Com o novo projeto, as exportações do produto tipicamente de exportação aumentam em $\mathrm{X}_{2}-\mathrm{X}_{0}$ e deslocam a oferta de dólares de SS para S'S'. Novamente, se fosse mantido o déficit da balança comercial, haveria uma tendência para que a taxa de câmbio caísse de $\mathrm{E}_{0}$ para $\mathrm{E}_{1}$.

A esta taxa de câmbio mais baixo sabe-se que haverá um benefício social correspondente à soma das áreas hachuradas $\mathrm{X}_{1} \mathrm{ABX}_{0} \mathrm{e}_{0} \mathrm{EFM}_{1}$. Deste modo, o preço social por unidade de dólar gerado pelo projeto é a divisão das áreas pelo volume de dólares gerado. Pode-se ainda imaginar um terceiro exemplo de projeto que ao invés de favorecer a balança comercial implicaria um acréscimo nas importações (por exemplo, ao invés de um produto tipicamente de importação, considere as importações formadas por insumos básicos ou equipamentos). Novamente, a conclusão seria que a taxa de câmbio social corresponde à soma de áreas sob curvas $S^{*} S^{*}$ e $D^{*} D^{*}$, dividida pelo valor em dólares da mudança na balança comercial.

Além disto, imaginando-se funções de oferta e demanda aproximadamente lineares, o passo seguinte seria constatar que a taxa social independe da magnitude do efeito na balança comercial. Após estas observações, pode-se generalizar a expressão (4) para um grande número de produtos:

$$
E^{*}=E\left[\frac{\sum_{i} \varepsilon^{\prime}{ }_{i} X_{i}\left(1+t_{x i}^{*}\right)^{-1}+\sum_{j}\left|\eta_{j}^{\prime}\right| M_{j}\left(1+t_{m j}^{*}\right)}{\sum_{i} \varepsilon_{i}^{\prime} X_{i}+\sum_{j}\left|\eta_{j}^{\prime}\right| M_{j}}\right]
$$

Onde:

$\mathrm{E}^{*}=$ custo de oportunidade da divisa;

$\mathrm{E}=$ taxa de câmbio vigente;

$\varepsilon_{\mathrm{i}}^{\prime}=$ elasticidade-preço da oferta de exportação de cada classe i de produtos em relação à taxa de câmbio;

$\eta_{\mathrm{j}}^{\prime}=$ elasticidade-preço da demanda de importação de cada classe $\mathrm{j}$ de produtos em relação à taxa de câmbio;

$\mathrm{X}_{\mathrm{i}}=$ valor da exportação em dólares da classe i de produtos;

$\mathrm{M}_{\mathrm{j}}=$ valor da importação em dólares da classe $\mathrm{j}$ de produto;

$\mathrm{t}^{*}{ }_{\mathrm{xi}}=$ soma das distorções no mercado de fatores e tarifas sobre as exportações de cada classe i de produtos; e

$\mathrm{t}^{*}{ }_{\mathrm{mj}}=$ soma das distorções no mercado de fatores e tarifas sobre as importações de cada classe $\mathrm{j}$ de produtos. 
Figura 3 - Efeitos de um projeto na balança comercial: o acréscimo na exportação

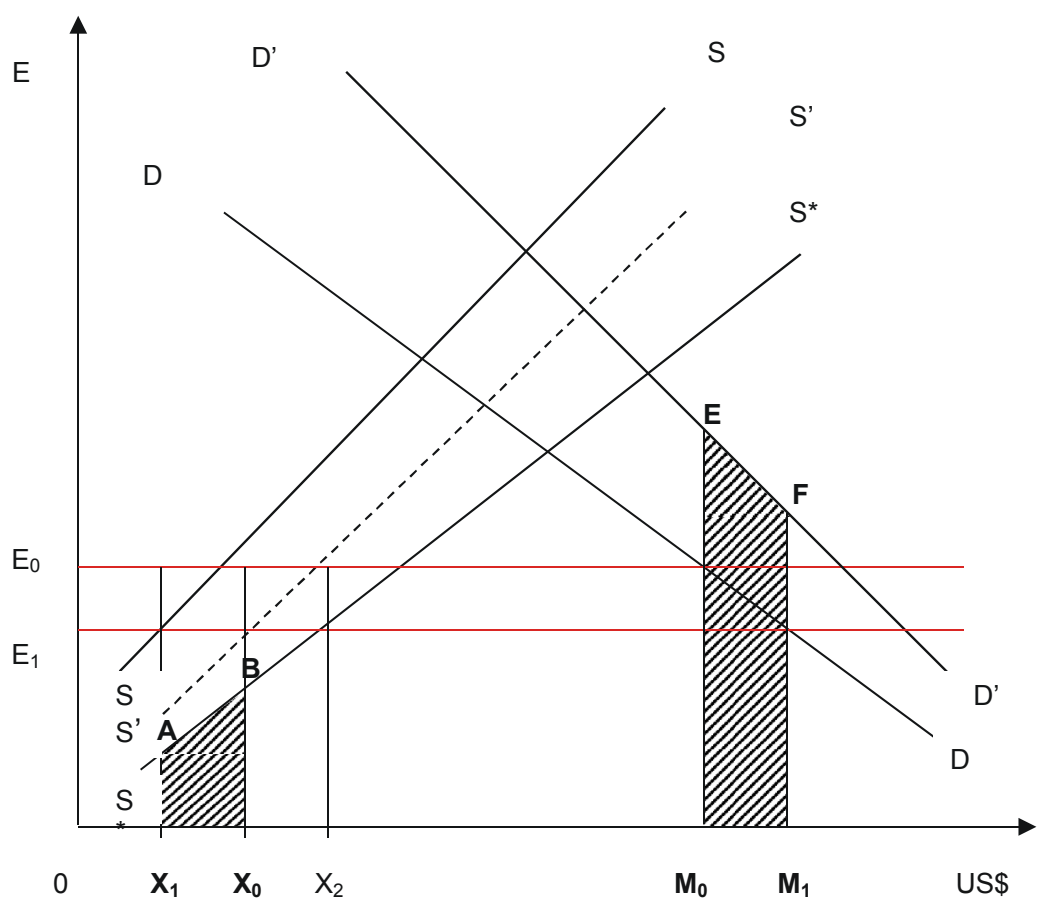

Adotando-se, ainda, a definição de tarifa média (com distorção) de exportação:

$$
T_{x}=\frac{\sum_{i} \varepsilon^{\prime}{ }_{i} X_{i}\left(1+t_{i}^{*}\right)}{\sum_{i} \varepsilon^{\prime}{ }_{i} X_{i}}, \text { onde } T_{x}=\overline{\left(1+t_{x}^{*}\right)^{-1}}
$$

e para importação:

$$
T_{m}=\frac{\sum_{j}\left|\eta_{i}^{\prime}\right| M_{j}\left(1+t_{j}^{*}\right)}{\sum_{j}\left|\eta_{j}^{\prime}\right| M_{j}}, \text { onde } T_{m}=\left(\overline{1+t_{m}^{*}}\right)
$$

e as elasticidades médias de exportação:

$$
\bar{\varepsilon}^{\prime}=\frac{\sum_{i} \varepsilon_{i}^{\prime} X_{i}}{\sum_{i} X_{i}}, \text { onde } X=\sum_{i} X_{i}
$$


e de importação:

$$
\overline{\eta^{\prime}}=\frac{\sum_{j} \eta^{\prime}{ }_{j} M_{j}}{\sum_{j} M_{j}} \text {, onde } M=\sum_{j} M_{j}
$$

e substituindo-se na expressão (5) resulta em:

$$
E^{*}=E\left[\frac{\overline{\varepsilon^{\prime}} T_{x} X+\left|\overline{\eta^{\prime}}\right| T_{m} M}{\overline{\varepsilon^{\prime}} X+\left|\overline{\eta^{\prime}}\right| M}\right]
$$

ou, melhor ainda, a taxa de câmbio social pode ser interpretada como:

$$
\frac{E^{*}}{E}=\left[\frac{\overline{\varepsilon^{\prime}} T_{x} X+\left|\overline{\eta^{\prime}}\right| T_{m} M}{\overline{\varepsilon^{\prime} X+\left|\overline{\eta^{\prime}}\right|} M}\right]
$$

De modo geral, mesmo os economistas que adotam o enfoque de Harberger (1972), incluindo o próprio, ignoram as distorções prévias nos mercados domésticos de fatores. Logo, a única distorção existente é o esquema de tarifas e subsídios aduaneiros, ou seja,

$$
\begin{aligned}
& \left(1+t_{i}^{*}\right)=\left(1+t_{i}\right) \\
& \left(1+t_{j}^{*}\right)=\left(1+t_{j}\right)
\end{aligned}
$$

Esta hipótese deve ser considerada como simplificadora, pois o seu emprego indiscriminado pode distorcer seriamente o valor da taxa de câmbio social.

\section{RESUltados E DisCUSSÃO}

Na estimativa da taxa de câmbio social, a partir do modelo do custo de oportunidade da divisa, desenvolvido anteriormente, foram utilizados os dados de importação $(\mathrm{M})$ e exportação (X) da balança de pagamentos publicados pela Revista Conjuntura Econômica da Fundação Getúlio Vargas (Tabela A.1). As exportações compreendem: produtos básicos, manufaturados e outros; e as importações: petróleo, bens de capital e outros. Para a taxa de câmbio nominal e efetiva real (Tabela A.2) e para as tarifas de importação foram utilizados os dados da tarifa nominal média (cenário 1) e a tarifa efetiva (cenário 2) estimada por Kume, Piani, e Souza (2000) para o período 1980-1998 e estimativas de Tyler (2003) para 1999-2003. ${ }^{13}$ Finalmente, com relação às elasticidades-preço de exportação e importação foram utilizadas as estimativas feitas por Carvalho e De Negri (2000), Rezende (1997), De La Cal (1981) e Tyler (1976), apresentadas em negrito na Tabela 1.

13 Os dados utilizados no cálculo da taxa de câmbio social são apresentados na Tabela 1 e nas Tabelas A.1, A.2 e A.3 do Apêndice. Com relação aos coeficientes de elasticidade-preço, foram examinadas e avaliadas as estimativas de diversos autores na literatura pertinente, não parecendo haver maiores discrepâncias em suas estimativas, que são apresentadas na Tabela 1. Desta forma, os coeficientes utilizados podem ser considerados representativos de elasticidades médias. As elasticidades usadas no cálculo da taxa de câmbio estão em negrito na Tabela 1. Para as exportações brasileiras anteriores a 1997, portanto, antes da Lei Kandir, considerou-se uma distorção média de 13\%, relativa à incidência de ICMS. As estimativas de Tyler foram realizadas para uma pesquisa em andamento, ainda não publicada. 
Tabela 1 - Estimativas do coeficiente de elasticidade-preço de exportação e importação

\begin{tabular}{|c|c|c|}
\hline Estimativa & $\begin{array}{l}\text { Elasticidade-preço da oferta } \\
\text { de exportações }(\varepsilon)\end{array}$ & $\begin{array}{c}\text { Elasticidade-preço da demanda } \\
\text { de importações }(\eta)\end{array}$ \\
\hline \multicolumn{3}{|l|}{ CARVALHO \& DE NEGRI (2000) } \\
\hline produtos básicos & 0,123 & $-1,342$ \\
\hline importações mundiais (PB) & 0,655 & - \\
\hline \multicolumn{3}{|l|}{ RESENDE (1997) } \\
\hline Importações totais (curto prazo) & - & $-0,540$ \\
\hline Importações totais (longo prazo) & - & $-0,083$ \\
\hline \multicolumn{3}{|l|}{ VARGAS (1993) } \\
\hline produtos básicos & 1,890 & $-1,040$ \\
\hline produtos básicos* & - & $-0,620$ \\
\hline \multicolumn{3}{|l|}{ DE LA CAL (1981) } \\
\hline importações totais (curto prazo) & - & $-0,180$ \\
\hline importações totais (longo prazo) & - & $-1,488$ \\
\hline produtos básicos & 0,544 & - \\
\hline produtos manufaturados & 0,852 & - \\
\hline bens de capital & - & $-1,020$ \\
\hline petróleo & - & 0,313 \\
\hline \multicolumn{3}{|l|}{ CARVALHO \& HADDAD (1980) } \\
\hline produtos básicos & 0,589 & - \\
\hline produtos manufaturados & 0,576 & - \\
\hline importações mundiais (PB) & 0,786 & - \\
\hline importações mundiais (PM) & 2,825 & - \\
\hline \multicolumn{3}{|l|}{ LEMGRUBER (1976) } \\
\hline importações totais & - & $-0,495$ \\
\hline bens de capital & - & $-0,727$ \\
\hline bens de consumo intermediário & - & $-0,023$ \\
\hline bens de consumo final & - & $-0,213$ \\
\hline petróleo & - & 0,663 \\
\hline \multicolumn{3}{|l|}{ TYLER (1976) } \\
\hline Produtos manufaturados & 0,878 & - \\
\hline Importações mundiais (PM) & 0,003 & - \\
\hline \multicolumn{3}{|l|}{ SUPLICY (1976) } \\
\hline importações totais & - & $-0,134$ \\
\hline produtos básicos & 0,567 & - \\
\hline produtos manufaturados & 0,872 & - \\
\hline importações mundiais (PB) & 1,183 & - \\
\hline importações mundiais (PM) & 2,021 & - \\
\hline \multicolumn{3}{|l|}{ DOELLINGER et alii (1971) } \\
\hline produtos básicos & 2,120 & - \\
\hline produtos manufaturados & 1,480 & - \\
\hline
\end{tabular}

PB - produtos básicos; PM - produtos manufaturados e importações sem trigo e petróleo.

Fonte: Referência Bibliográfica. 
Os resultados do cálculo da taxa de câmbio social, para o período 1980/2003, são apresentados na Tabela 2 e mostram que a taxa de câmbio social foi sempre superior à taxa de câmbio vigente. A formulação matemática empregada no cálculo da taxa de câmbio social é a equação (11), onde o custo de oportunidade da divisa é dado pela relação $\mathrm{E}^{*} / \mathrm{E}$. No período considerado houve uma queda gradual no valor da taxa de câmbio social, de 17,4\% em 1980 para 4,5\% em 2003 (usando a tarifa nominal) e de 20,3\% em 1980 para 7,4\% em 2003 (usando a tarifa efetiva). Deste modo, os resultados da pesquisa mostram que a distorção média no mercado de câmbio em 1980 era cerca de 20\%, enquanto que em 2003 esta distorção estaria em torno de 7,4\%.

Tabela 2 - Estimativa da taxa de câmbio social para o Brasil, 1980/2003

\begin{tabular}{ccc}
\hline Ano & Taxa de Câmbio Social com Tarifa Nominal & Taxa de Câmbio Social com Tarifa Efetiva \\
\hline 1980 & 1,1742 & 1,2029 \\
1981 & 1,1334 & 1,1530 \\
1982 & 1,1315 & 1,1514 \\
1983 & 1,0781 & 1,0891 \\
1984 & 1,0521 & 1,0674 \\
1985 & 1,0659 & 1,0839 \\
1986 & 1,1306 & 1,1636 \\
1987 & 1,1817 & 1,2072 \\
1988 & 1,1251 & 1,1441 \\
1989 & 1,1155 & 1,1463 \\
1990 & 1,1181 & 1,1585 \\
1991 & 1,0956 & 1,1237 \\
1992 & 1,0608 & 1,0718 \\
1993 & 1,0610 & 1,0720 \\
1994 & 1,0619 & 1,0733 \\
1995 & 1,0744 & 1,0910 \\
1996 & 1,0744 & 1,0989 \\
1997 & 1,0917 & 1,1120 \\
1998 & 1,0912 & 1,1079 \\
1999 & 1,0841 & 1,0999 \\
2000 & 1,0224 & 1,0270 \\
2001 & 1,0692 & 1,0921 \\
2002 & 1,0550 & 1,0814 \\
2003 & 1,0452 & 1,0741 \\
\hline
\end{tabular}

Fonte: Elaboração da pesquisa.

Na representação gráfica da evolução da taxa de câmbio social para o período considerado, apresentada na Figura 4, é possível perceber quatro fases distintas em relação à evolução da taxa de câmbio social no período em análise.

A primeira fase compreende o período que vai de 1980 até 1985, quando a taxa de câmbio social evolui em queda, com uma oscilação de $20 \%$ até cerca de $8 \%$ superior à taxa de câmbio vigente. A segunda fase refere-se ao período 1986/1992, onde há uma elevação da taxa de câmbio social, com uma oscilação variando de $16 \%$ a $7 \%$. A terceira fase compreende o período a partir do ano de 
1992 até 1999, onde se observa uma certa estabilização da variação da taxa com uma oscilação que vai de $7 \%$ a $10 \%$. Finalmente, uma quarta fase a partir de 1999, coincidindo com a adoção do regime cambial flexível, onde se pode observar uma redução acelerada da taxa de câmbio social em 2000 evoluindo para uma redução mais gradual a partir de 2001.

Figura 4 - Evolução da estimativa da taxa de câmbio social, 1980/2003

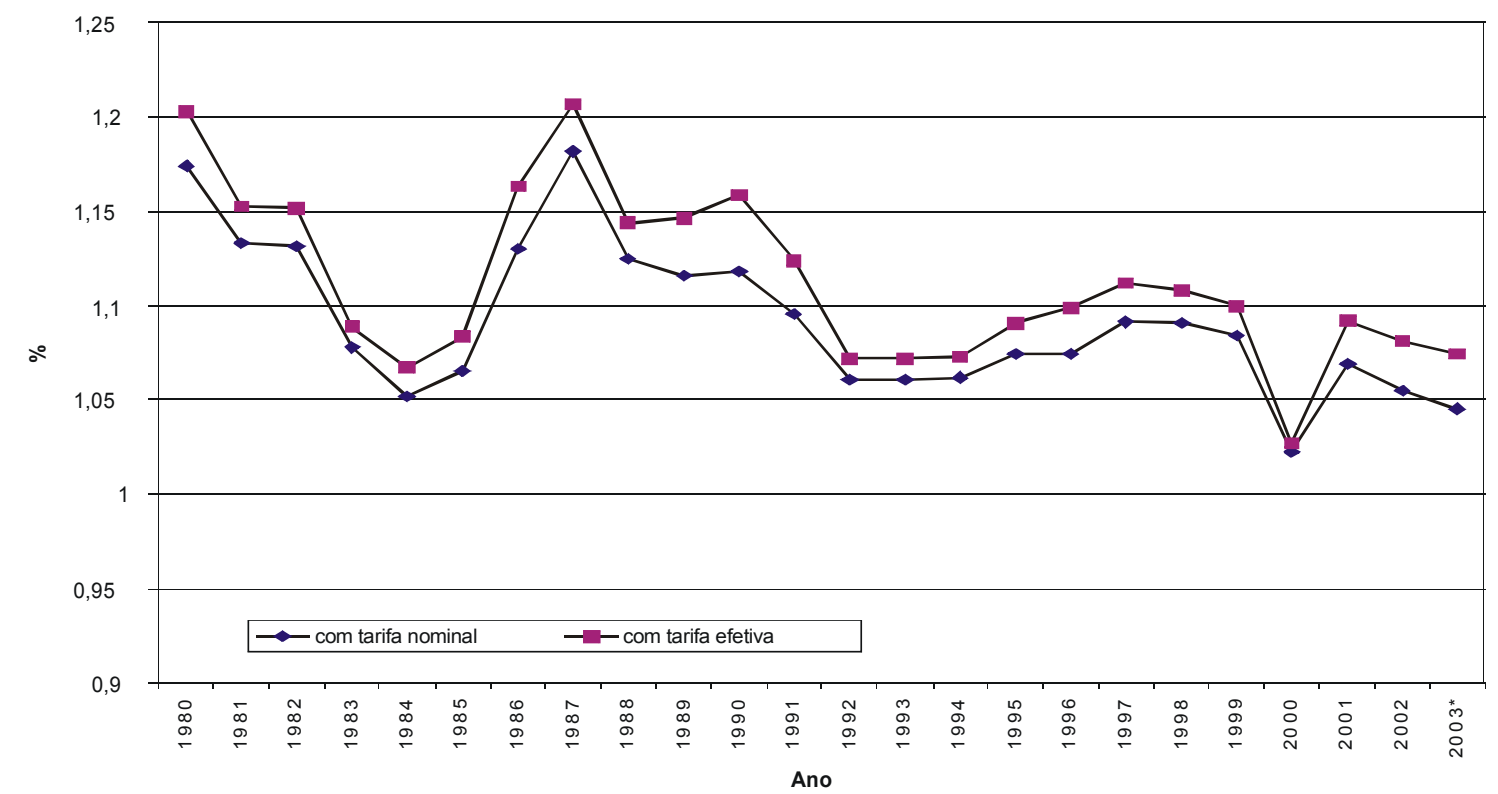

\section{CONCLUSÕES}

Os déficits e os superávits do balanço de pagamentos são efeitos e não causas. Quando ocorrem de modo sistemático, há necessidade de procurar suas causas para corrigi-las. Num mercado totalmente livre e não sujeito à intervenção do estado, essa correção é feita pela própria taxa de câmbio.

A hipótese inicial desta pesquisa, de que a abertura comercial e a mudança do regime cambial, em janeiro de 1999, fossem acarretar uma redução considerável da taxa de câmbio social, foi efetivamente comprovada. Contudo, eventualmente, a redução gradual da taxa social de câmbio, no período considerado, deveu-se muito mais ao processo de abertura comercial iniciado no Brasil no final dos anos oitenta.

O efeito da mudança na política cambial é mais demorado. Neste sentido, os resultados da pesquisa, grosso modo, podem ser comparados com a análise da política brasileira de importação feita por Kume, Piani e Souza (2000), na qual são descritos as mudanças radicais observadas no período 1987/1998 e os seus reflexos no comércio exterior. Segundo este trabalho, a política brasileira de importações pode ser subdividida em quatro etapas. Na primeira, entre 1987 e 1989, a tarifa nominal média caiu de $54,7 \%$ para $29,4 \%$ e a tarifa efetiva de $67,8 \%$ para $38,8 \% .{ }^{14}$ Contudo, a ênfase da mudança foi somente nas parcelas redundantes das tarifas legais, enquanto as restrições não-

14 Adicionalmente à tarifa nominal, incidente sobre determinado produto, a tarifa efetiva considera também as tarifas aplicadas aos seus insumos que oneram as estruturas de custos. Em outras palavras, a tarifa efetiva mede o aumento no valor adicionado proporcionado pela estrutura tarifária em relação ao valor adicionado sem a presença de tarifas (situação de livre-comércio). Para mais detalhes e metodologias alternativas para estimar a tarifa efetiva ver Williamson (1989, p. 82-83, op. cit). 
tarifárias e os regimes especiais de tributação, que permitiam importações com isenção ou redução das tarifas, foram mantidas intactas. Conseqüentemente, os efeitos sobre o volume de importações e a produção doméstica foram nulos. Neste período, os resultados desses autores mostram uma redução da taxa de câmbio social de $18 \%$ para $11 \%$, usando-se a tarifa nominal média, e de $21 \%$ para $15 \%$, usando-se a tarifa efetiva.

Na segunda fase, após a extinção, em 1990, das barreiras administrativas que dificultavam as compras do exterior, foi cumprido um cronograma de reduções tarifárias no período 1991-93, que diminuiu, no final do processo, a tarifa legal média para $12,5 \%$ e a tarifa efetiva para $15,2 \%$. Neste estágio, os controles sobre as importações eram exercidos exclusivamente pela tarifa aduaneira, em níveis compatíveis com os vigentes em outras economias em desenvolvimento. Houve uma queda considerável. Em 1993 a taxa de câmbio social estimada era cerca de 6\% (tarifa nominal média) e $7 \%$ (tarifa efetiva) acima da taxa oficial.

Na terceira etapa, em 1994, as reduções tarifárias foram aceleradas em decorrência da necessidade de impor maior disciplina aos preços domésticos, via ampliação da competição externa, o que ensejou ainda a antecipação dos compromissos assumidos no MERCOSUL para a fixação da tarifa externa comum. Estas medidas acarretaram uma diminuição da tarifa nominal média para 10,2\% e da tarifa efetiva para $12,3 \%$. Como resultado, as aquisições no exterior se intensificaram e o Brasil passou a ter déficits comerciais a partir do último bimestre daquele ano, fato que não ocorria desde janeiro de $1987 .^{15}$

Na quarta fase, referente ao período 1995-98, o País sofreu um retrocesso no processo de liberalização das importações que tinha sido gradualmente implementado desde 1988. A crise mexicana de dezembro de 1994 explicitou a gravidade dos riscos de se manter déficits elevados em transações correntes e levou o governo brasileiro a aumentar as tarifas de automóveis, bens eletroeletrônicos de consumo e produtos têxteis, entre outros. Ao mesmo tempo, voltou-se a aplicar barreiras não-tarifárias a produtos estrangeiros, como pagamento antecipado das importações, cumprimento de exigências sanitárias e instituição de uma extensa lista de produtos para os quais voltava a ser requerida uma licença prévia de importação. Em 1995, a tarifa nominal média aumentou para $12,2 \%$ e a tarifa efetiva para $15,6 \%$, enquanto a taxa de câmbio social estimada era $7,4 \%$, usando-se a tarifa nominal média, e de $9,1 \%$, usando-se a tarifa efetiva.

Por fim, em novembro de 1997, em razão dos reflexos da crise asiática no mercado financeiro internacional, o governo brasileiro elevou as tarifas aduaneiras em três pontos de porcentagem, fazendo com que a tarifa média subisse para $14,9 \%$ e a tarifa efetiva para 18,6\%. Após uma relativa estabilização, em 1997 a estimativa da taxa de câmbio social tem o seu primeiro incremento: passa para $9,1 \%$ usando-se a tarifa média nominal e 11,2\% usando-se a tarifa efetiva.

Apesar do retrocesso verificado a partir do ano de 1995, foi expressivo o alcance das medidas de abertura comercial adotadas no Brasil desde 1988. As tarifas nominal e efetiva foram substancialmente reduzidas e, em conseqüência, obteve-se maior uniformidade na estrutura dos incentivos proporcionada pelas tarifas aduaneiras, o que significa menor intervenção governamental na alocação dos recursos escassos da sociedade. Contudo, não houve uma alteração importante no ordenamento das atividades segundo o grau de proteção efetiva. Os efeitos da abertura comercial, bem como da política de câmbio livre, só serão sentidos a médio e longo prazo, mas já se pode perceber a indicação dos seus efeitos pela tendência declinante da taxa de câmbio social contribuindo para uma redução considerável das distorções na economia brasileira.

15 Veja Kume, Piani e Souza (2000, op. cit). 
Como afirma Rolf Kuntz, o regime cambial flexível pode ser mais instável que o outro, assim como é mais fácil cair da bicicleta que de avião. Contudo, o importante é a diferença entre as conseqüências de um tombo e de outro. ${ }^{16}$

\section{APÊNDICE}

Tabela A.1 - Comportamento da balança comercial brasileira, 1980/2003 (US\$ milhões)

\begin{tabular}{|c|c|c|c|c|c|c|c|}
\hline \multirow[t]{2}{*}{ Ano } & \multicolumn{3}{|c|}{ Exportações } & \multicolumn{3}{|c|}{ Importações } & \multirow[t]{2}{*}{ Saldo } \\
\hline & Básicos & Manufaturados & Total & Petróleo & Bens de Capital & Total & \\
\hline 1980 & 8428 & 9028 & 20133 & 9405 & 4381 & 22954 & -2821 \\
\hline 1981 & 8852 & 11884 & 23292 & 10600 & 4023 & 22092 & 1200 \\
\hline 1982 & 8195 & 10253 & 20176 & 9568 & 3272 & 19395 & 781 \\
\hline 1983 & 8484 & 11275 & 21899 & 8607 & 2506 & 15429 & 6470 \\
\hline 1984 & 8755 & 15132 & 27006 & 6735 & 2151 & 13916 & 13090 \\
\hline 1985 & 8538 & 14063 & 25642 & 5418 & 2480 & 13154 & 12488 \\
\hline 1986 & 7280 & 12404 & 22349 & 2786 & 3464 & 14045 & 8304 \\
\hline 1987 & 8022 & 14839 & 26224 & 3859 & 3958 & 15053 & 11171 \\
\hline 1988 & 9411 & 19187 & 33789 & 3192 & 4195 & 14605 & 19184 \\
\hline 1989 & 9548 & 18634 & 34383 & 3390 & 4576 & 18263 & 16120 \\
\hline 1990 & 8748 & 16988 & 31414 & 4354 & 3989 & 20661 & 10753 \\
\hline 1991 & 8737 & 17757 & 31620 & 3370 & 4256 & 21041 & 10579 \\
\hline 1992 & 8840 & 21396 & 35862 & 3069 & 4499 & 20554 & 15308 \\
\hline 1993 & 9366 & 23473 & 38597 & 2138 & 5091 & 25659 & 12938 \\
\hline 1994 & 11058 & 24959 & 43545 & 2339 & 7575 & 33105 & 10440 \\
\hline 1995 & 10969 & 25565 & 46506 & 2587 & 11445 & 49664 & -3158 \\
\hline 1996 & 11900 & 26413 & 47747 & 3461 & 12705 & 53301 & -5554 \\
\hline 1997 & 14474 & 29190 & 52990 & 3220 & 16993 & 61347 & -8357 \\
\hline 1998 & 12970 & 29369 & 51120 & 1964 & 16089 & 57594 & -6474 \\
\hline 1999 & 11827 & 27328 & 48011 & 2124 & 13555 & 49295 & -1284 \\
\hline 2000 & 12562 & 32528 & 55086 & 3190 & 13593 & 55837 & -751 \\
\hline 2001 & 15341 & 32900 & 58223 & 3193 & 14801 & 55581 & 2642 \\
\hline 2002 & 16952 & 33001 & 60362 & 3304 & 11592 & 47235 & 13127 \\
\hline 2003 & 21179 & 39654 & 73085 & 3840 & 10344 & 48249 & 24836 \\
\hline $2004^{*}$ & 13663 & 23024 & 43306 & 3150 & 5534 & 28257 & 15049 \\
\hline
\end{tabular}

* Dados: até junho.

Fonte: ConjunturaEconômica.

16 Citado por Maia (2003, p. 326). 
Tabela A.2 - Taxa de câmbio nominal e efetiva real, 1980/2003 $(1998=100)$

\begin{tabular}{lcc}
\hline Ano & Taxa de Câmbio Nominal & $\begin{array}{c}\text { Taxa de Câmbio } \\
\text { Efetiva Real }^{* *}\end{array}$ \\
\hline 1980 & - & 148,90 \\
1981 & - & 150,63 \\
1982 & - & 145,14 \\
1983 & - & 159,88 \\
1984 & - & 146,87 \\
1985 & - & 161,13 \\
1986 & - & 160,82 \\
1987 & - & 170,53 \\
1988 & - & 147,56 \\
1989 & - & 113,44 \\
1990 & 0,01 & 134,76 \\
1991 & 0,02 & 139,10 \\
1992 & 0,33 & 128,22 \\
1993 & 8,33 & 114,71 \\
1994 & 70,52 & 91,27 \\
1995 & 80,33 & 102,21 \\
1996 & 86,03 & 100,49 \\
1997 & 92,36 & 96,71 \\
1998 & 100,00 & 100,00 \\
1999 & 152,87 & 117,61 \\
2000 & 162,86 & 110,84 \\
2001 & 196,00 & 120,79 \\
2002 & 300,80 & 154,65 \\
2003 & 233,30 & 115,79 \\
$2004^{* * *}$ & 249,12 & 103,88 \\
\hline & & \\
\hline
\end{tabular}

* Taxa de câmbio comercial - média mensal do mês de dezembro - venda.

* Taxa de câmbio efetiva real do mês de dezembro - IPA-DG - exportações.

*** Dados até agosto.

Fonte: http://www.ipeadata.gov.br/ 
Tabela A.3 - Tarifa nominal e tarifa efetiva (importações), 1987/2003 (em \%)

\begin{tabular}{cccccccc}
\hline & \multicolumn{3}{c}{ Tarifa Nominal } & & \multicolumn{3}{c}{ Tarifa Efetiva } \\
\cline { 2 - 3 } & Petróleo & Bens de Capital & Outros & & Petróleo & Bens de Capital & Outros \\
\hline 1987 & 15,6 & 49,0 & 57,5 & & 8,3 & 47,5 & 77,1 \\
1988 & 5,6 & 46,8 & 39,6 & & $-2,9$ & 50,2 & 52,1 \\
1989 & 1,9 & 38,8 & 32,1 & & $-5,4$ & 44,0 & 46,5 \\
1990 & 3,3 & 37,2 & 30,5 & & $-3,4$ & 41,5 & 47,7 \\
1991 & 1,7 & 28,5 & 23,6 & & $-4,0$ & 31,3 & 34,8 \\
1992 & 0,6 & 20,2 & 15,7 & & $-4,0$ & 22,1 & 20,3 \\
1993 & 0,0 & 19,1 & 13,5 & & $-5,0$ & 21,7 & 16,7 \\
1994 & 0,0 & 19,0 & 11,2 & & $-4,9$ & 22,4 & 13,6 \\
1995 & 0,0 & 16,5 & 12,8 & & $-2,4$ & 18,0 & 17,1 \\
1996 & 0.0 & 15,5 & 13,0 & & $-1,8$ & 16,7 & 19,9 \\
1997 & 0,0 & 17,8 & 15,6 & & $-2,2$ & 18,6 & 21,6 \\
1998 & 0,0 & 17,7 & 15,5 & & $-2,2$ & 18,6 & 20,2 \\
1999 & 0,0 & 17,6 & 14,8 & & $-1,8$ & 18,2 & 19,6 \\
2000 & 0,0 & 17,1 & 14,1 & & $-1,6$ & 17,8 & 18,8 \\
2001 & 0,2 & 16,5 & 11,7 & & $-1,5$ & 18,0 & 18,6 \\
2002 & 0,4 & 15,2 & 10,3 & $-1,4$ & 18,0 & 18,4 \\
2003 & 0,5 & 14,4 & 9,2 & $-1,3$ & 18,0 & 18,4 \\
\hline
\end{tabular}

Fonte: Kume, Piani e Souza (2000) para 1987/1998 e Tyler (2003) para 1999/2003.

\section{BIBLIOGRAFIA}

Bacha, E. Taxas de câmbio de equilíbrio: formulação teórica e exemplificação. Revista Brasileira de Economia, v. 24, n. 1, p. 145-153, janeiro/março 1970.

Bacha, E.; Taylor, L. Foreign exchange shadow prices: a critical review of current theories. The Quarterly Journal of Economics, v. 85, n. 2, p. 197-224, 1971.

Carvalho, A.; De Negri, J. A. Estimação de equações de importação de produtos agropecuários para o Brasil (1977/1998). Brasília: IPEA, Texto para Discussão, n. 698, janeiro de 2000, 30p.

Carvalho, J. L.; Haddad, C. L. S. Estratégias comerciais e absorção de mão-de-obra no Brasil. Rio de Janeiro: Editora da FGV, 1980.

Contador, C. R. Projetos sociais - avaliação e prática. $4^{a}$ edição. São Paulo: Editora Atlas, 2000.

Corden, W. M. The normative theory of international trade. In: Jones, R. W.; Kenen, P. B. (Eds.), Handbook of international economics. North Holland, 1984.

De La Cal, Manuel S. Uma análise econométrica da balança comercial brasileira: 1965-1979. 1981. Dissertação (Mestrado), Universidade Federal Fluminense, Niterói.

Doellinger, C.; Faria, H. B. C.; Ramos, R. N. M.; Cavalcanti, L. C. Transformações da estrutura das exportações brasileiras: 1964/70. Rio de Janeiro: Editora do IPEA, 1973.

Ferreira, Léo R. A taxa de câmbio social no Brasil: MERCOSUL e abertura comercial. Rio de Janeiro: Letra Capital Editora, 2004. 
Gonçalves, R. Globalização financeira, liberalização cambial e vulnerabilidade externa da economia brasileira. In: Baumann, R. (Org.), O Brasil e a economia global. Rio de Janeiro: Editora Campus, 1996.

Harberger, A. C. (Org.), Project evaluation: collected papers. Chicago: Markham, 1972.

Kume, H.; Piani, G.; Souza, C. F. B. A política brasileira de importação no período 1987-98: descrição e avaliação. Rio de Janeiro: IPEA, maio de 2000, 27p. Mimeografado.

Lemgruber, A. C. O balanço de pagamentos do Brasil - uma análise quantitativa. Pesquisa e Planejamento Econômico, v. 6, n. 2, p. 313-52, agosto de 1976.

Licha, A. L. A instabilidade do câmbio no Brasil - onde está a fonte do atual desequilíbrio? Jornal dos Economistas, v. 145, n. 7, p. 3-4, julho de 2001.

Maia, J. M. Economia internacional e comércio exterior. $8^{\text {a }}$ edição. São Paulo: Editora Atlas, 2003.

Pinto, M. B. P. A taxa de câmbio virtual. Revista Brasileira de Economia, v. 43, n. 1, p. 19-30, janeiro/ março 1989.

Resende, M. F. C. Disponibilidade cambial e especificação da função de demanda de importações. Rio de Janeiro: IPEA, Texto para Discussão n. 506, agosto de 1997, 38p.

Suplicy, E. Os efeitos das minidesvalorizações na economia brasileira. Rio de Janeiro: Editora da FGV, 1976.

Tyler, W. G. Strengthening the policy environment for export growth in Brazil. Rio de Janeiro: FCE / UERJ, novembro de 2003 (trabalho em andamento).

. Manufactured export expansion and industrialization in Brazil. Kiel: Institut für Weltwirtschaft an der Universität, 1976.

Vargas, G. C. Tasa de cambio real efectiva y exportaciones brasileñas de productos manufacturados. Rio de Janeiro: IPEA/PNPE, Cadernos de Economia, n. 14, novembro de 1993, 84p. ${ }^{17}$

Williamson, J. A economia aberta e a economia mundial. Rio de Janeiro: Editora Campus, 1989.

17 Errata na publicação: Caderno de Economia N. 14 do IPEA, onde se lê Gloria Canales Vianna, leia-se Gloria Canales Vargas. 